\title{
Golden Eagle Flight Plan Online: A Web-Based Advisement Tool to Facilitate Developmental Advising
}

Dr. Chengyu Sun, California State University, Los Angeles

Dr. Deborah Won, California State University, Los Angeles

Deborah Won is an Associate Professor in Electrical and Computer Engineering at California State University, Los Angeles. Her specialization is in Biomedical Engineering and her scientific research area focuses on neuro-rehabilitative technology. Her educational research interests include use of Tablet PCs and technology to better engage students in the classroom as well as pedagogical and advisement approaches to closing the achievement gap for historically under-represented minority groups.

Dr. Emily L. Allen, California State University, Los Angeles

Dr. Emily Allen is Dean of the College of Engineering, Computer Science, and Technology at California State University, Los Angeles.

Mr. Harsh Gadhia, California State University, Los Angeles

Graduate Student Department of Computer Science, California State University, Los Angeles. 


\section{Golden Eagle Flight Plan Online: A Web-Based Advisement Tool to Facilitate Developmental Advising \\ Harsh Gadhia, Chengyu Sun, Deborah Won, and Emily Allen}

\section{Motivation}

Academic advisement, when carried out effectively, can help students to discover and build their professional identity, to perceive their college environment as one that is caring and welcoming, and to feel better connected to the University [1, 2]. Ultimately, good academic advisement improves student's chances of persisting in college [3, 4]. Here, at the College of Engineering, Computer Science, and Technology (ECST) at California State University, Los Angeles, the Golden Eagle Flight Plan (GEFP) has been developed to encourage a holistic, developmental advisement approach. The GEFP was one of the interventions in a new First-Year Experience at ECST (FYrE@ECST) program, which was piloted this 2015-16 academic year. The GEFP has undergone preliminary testing with the inaugural Fall '15 FYrE@ECST cohort. This work in progress describes the design of the online tool that was developed, presents the current implementation of the system, and results from the first academic quarter of the FYrE program.

\section{Purpose of the Golden Eagle Flight Plan}

The Golden Eagle Flight Plan - Online (GEFP) is a web-based developmental advising tool designed to promote a more holistic view of students' education and better encourage students to develop their own professional identity. As developmental advising lies on the opposite end of the spectrum from prescriptive advising, the GEFP encourages students to take greater responsibility over their own advising, rather than solely relying on the advisor to prescribe steps to a successful college career. The online tool enables students and advisors to keep track of the students' educational goals, or milestones, and progress toward reaching those milestones. Each milestone is classified both by the level at which advisors in our College believe students should aim to complete it and by the dimension of the student's college education under which that milestone falls. Thus the flight plan forms a matrix divided into stages of their career (i.e., from pre-frosh through senior level) and into "runways", which we categorized as 1) academic performance; 2) career preparation; and 3) leadership \& community engagement. Advisors for each degree program collaborate to identify the milestones most appropriate for students in that major throughout the various stages of the program.

\section{GEFP Online Implementation and Features}

The GEFP Online software system was designed to meet multiple objectives, including those listed below: 
1) Students view their own flight plans by logging into an online dashboard system using the same account information as their campus web login ID and password (Fig. 1).

2) Likewise, advisors are able to login to their own account, but they are able to view any student's plan using a search function.

3) Advisors can also be given administrator access. Users with an administrator role can create and modify the flight plan template for any major (Fig. 2).

4) Each student inherits a major-specific template (Fig. 3).

5) Students can keep track of milestones they have accomplished (Fig. 4)

6) Advisors can keep track of milestones their advisees have accomplished.

7) Students and advisors can communicate to each other through comments that can be saved for each milestone as well as for the overall plan for each student (Fig. 5).

8) GEFP Online also serves as an informational resource, as most milestones have hypertext links to a webpage that either provides more information about the milestone or actually assists the student in carrying out the milestone (e.g., a registration link for an event, a link to make an appointment, etc. See Fig. 4).

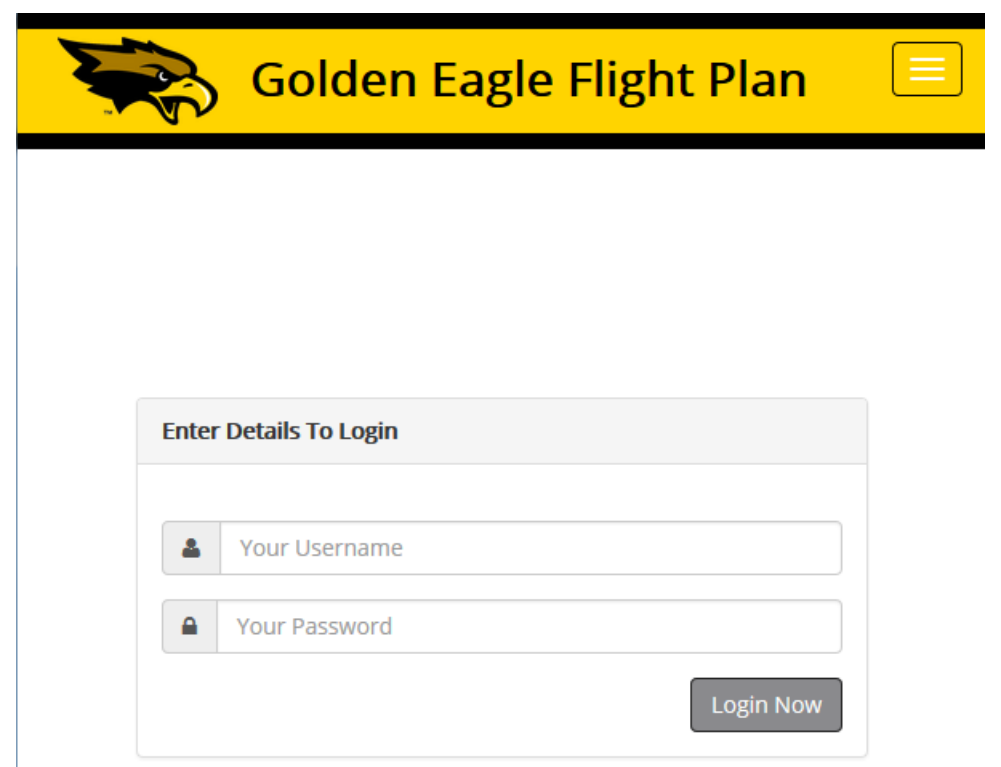

Figure 1) Login page for the GEFP Online. Users are assigned one of 3 roles: student, advisor, or administrator. 

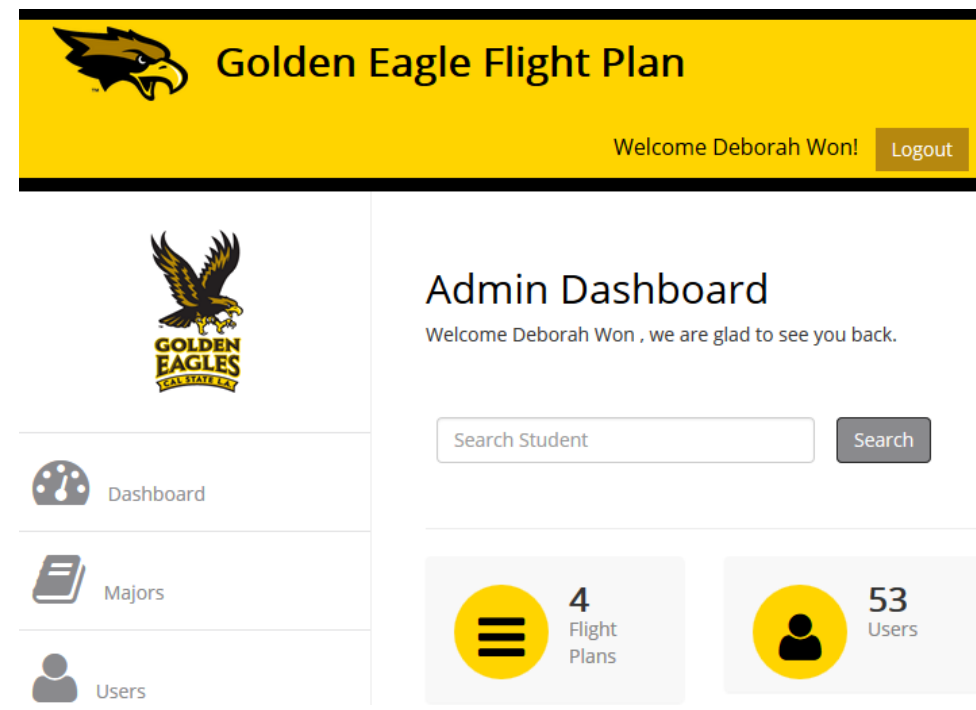

Fig. 2) Administrator dashboard view: Those given an Admin role can view and edit flight plan templates for any major and also have all the same functionality as Advisors.

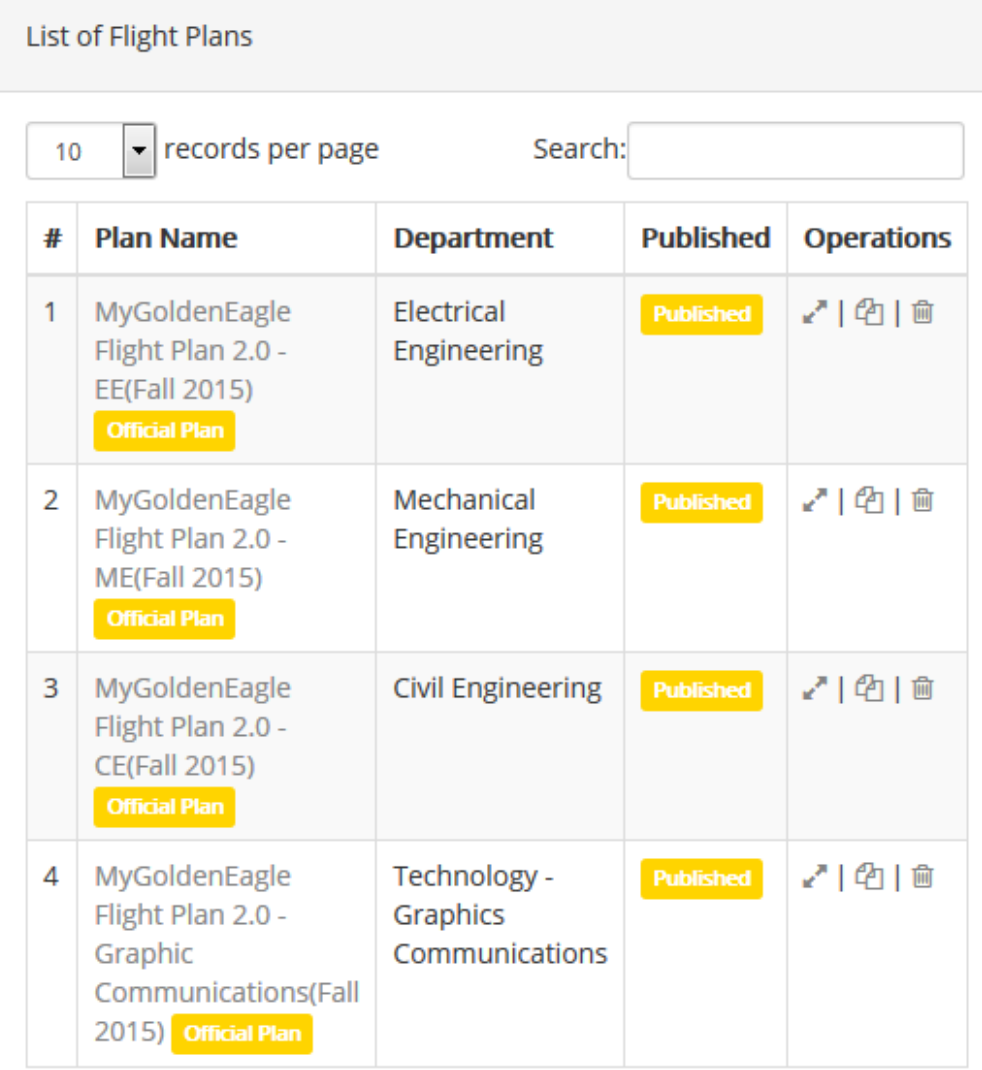

Fig. 3) Flight plan templates are created for each major degree program. Revisions can be made at any time by a GEFP administrator. Department advisors must agree on an annual current template for each major. 


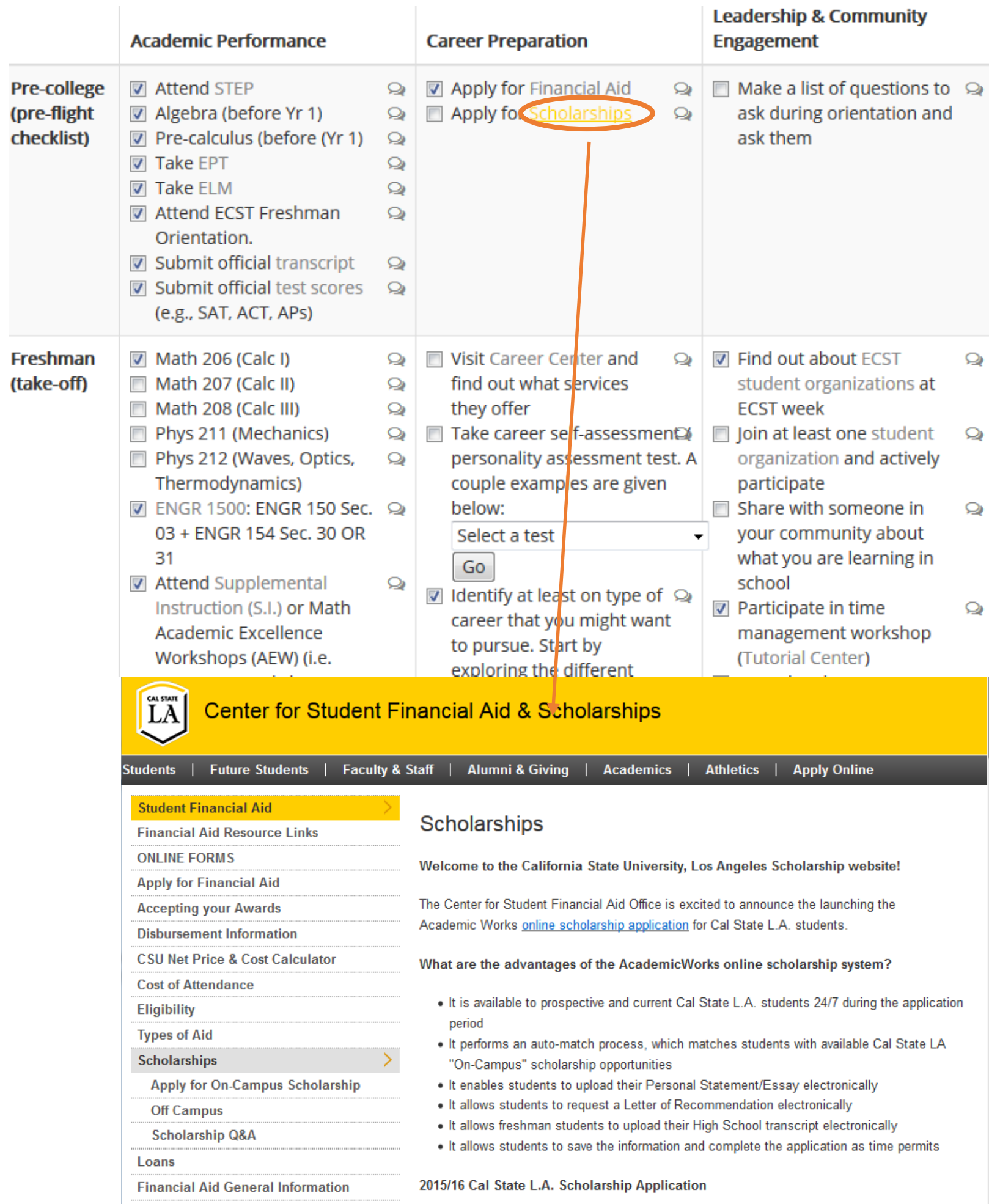

Fig. 4) Students mark off milestones as they are completed. They can also click on any of the many hypertext links and will be directed to a relevant page that might provide instructions on how to carry out the milestone or event registration details. 


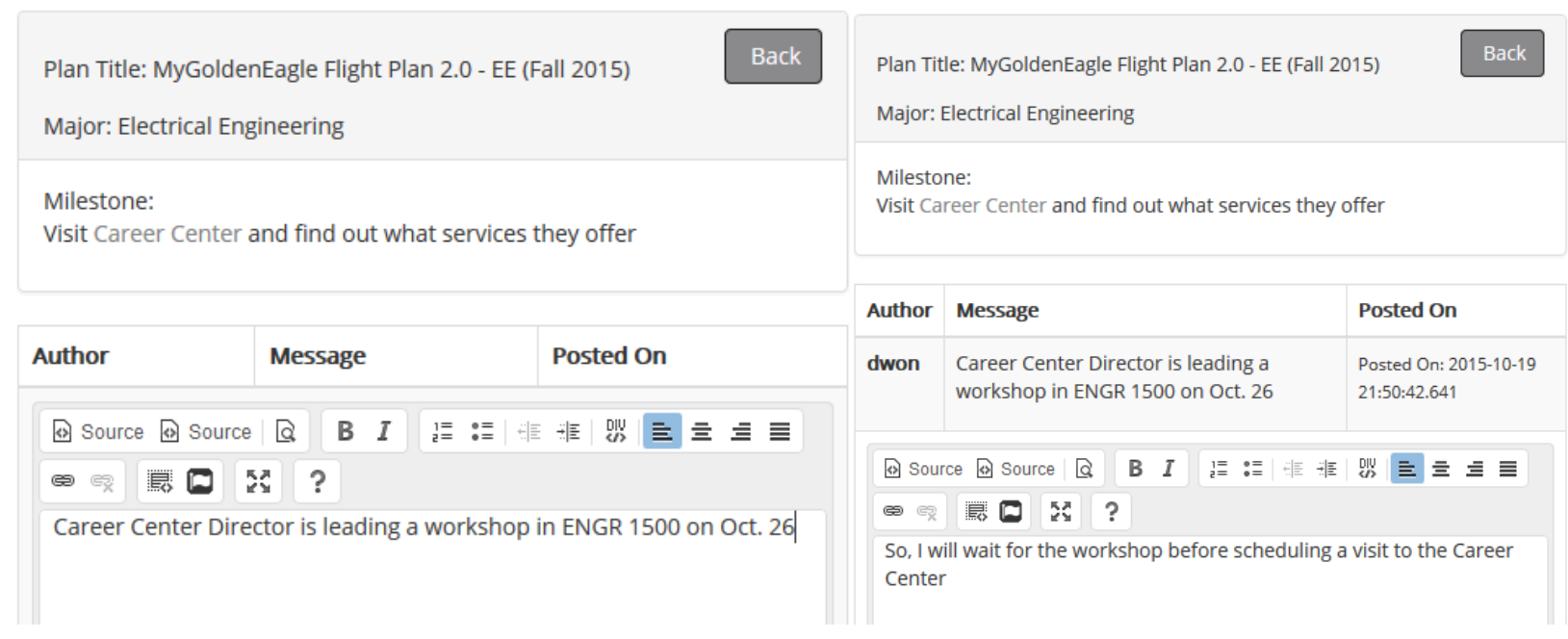

(a)

(b)

Fig. 5) (a) An advisor might provide a helpful comment on a particular milestone (shown from advisor's view). (b) The thread of comments is then saved for both student's and advisor's reference (shown from student view).

\section{Use of the GEFP by Students and Advisors}

The GEFP was pilot tested with the 32 students in the First-Year Experience program (FYrE@ECST).FYrE@ECST students were randomly selected from the incoming first-time freshmen majoring in engineering or technology who had completed the College's summer bridge program and had satisfied the pre-requisites for Calculus I by the start of the Fall term of their freshman year. FYrE students were introduced to the GEFP - Online during one of the first lectures of their gateway Introduction to Engineering and Technology course. The FYrE advisors from the ECST Student Advisement Center gave a presentation about the advisement center and how to use the Golden Eagle Flight Plan. This lecture was conducted in a computer lab so that students were given the opportunity to log into their GEFP accounts and try navigating through their flight plan for the first time while advisors were available to provide guidance. The FYrE advisors met once with each of the FYrE students during the Fall term and reviewed the student's flight plan with him or her during that advising appointment.

\section{Assessment results}

Two main approaches were taken to assess how students viewed the utility of the tool and what aspects, if any, they valued about the tool. A web-based anonymous survey was conducted at the end of the Fall quarter, i.e., after use of the tool for one quarter. In addition, backend request logging was implemented to assess how well various functions of the GEFP Online were utilized; that is, how frequently students referred to their GEFP during the academic year. One student withdrew from the College before request logging and survey data was collected. As part of the end-of-quarter assessment, the survey was completely voluntary and was sent out at the 
beginning of their winter quarter break, so as not to conflict with final exams. We obtained a $53 \%$ response rate (17 out of 32 students) on the survey.

The first question on the survey was designed to ascertain the students' perspective on the purpose of the Golden Eagle Flight Plan. In response to the question "How would you describe what the Golden Eagle Flight Plan is to someone who has not heard of it before?”, the students provided the following verbatim answers:

- Its a step by step guide on what you sgould be doing to succed

- It is a way to organize your academic profile and all the things you do to further your education and career.

- Golden Eagle Flight Plan help me check off from the list to see whether I'm on the right path to success.

- The Golden Eagle Flight Plan lets you know what you are expected and supposed to do to on your whole college at CSULA and organizes everything in a yearly basis. It contains direct links to whatever you needed to know.

- Its basically a checklist of things you should do while in the engineering program at Cal State LA.

- The golden eagle flight plan is an organizer for academic goals.

- It is helpful to manage the different tasks needed to complete during a college experience per quarter.

- It's like a guideline to meet the requirements that companies look for.

- A tool to track your path to success

- The Golden Eagle flight pen is a program that can help students to track themselves in their goal for achievement in their studies and to help them organize their classes.

- Guidelines to be successful in school.

- It is basically a year long planner / to do list that helps you get involved with community and classmates.

- It was very enjoyable being able to interact with your community and just learning the basis to further your interest.

- A guide to keep yourself busy during freshman year and helps you get more familiar with the campus.

These responses aligned well with the intended purpose of the GEFP.

After this open-ended question, students were asked to express their agreement with the following statements on a 5-level Likert scale ranging from strongly disagree to strongly agree:

("How much do you agree with the following statements regarding the Golden Eagle Flight Plan?”)

1. I gain a lot of information by using the GEFP.

2. I find the GEFP difficult to use.

3. I learn more about how to make the most of my college experience by using the GEFP. 
4. Using the GEFP motivates me to take advantage of opportunities available to me as an ECST student.

5. I have a better understanding of what I need to become a successful engineer by using the GEFP

6. I learn more about myself by using the GEFP.

7. I would like for advisors to use the GEFP when advising me

8. I feel the GEFP is more INCONVENIENT than it is useful

Statements 3 and 5 best summarize the goal and purpose of the GEFP. Statement 8 was an important measure to gauge how likely it would be that the students would be willing to use the tool, given that students have to remind themselves to log in and use it. A histogram of responses for each of these three selected statements is presented below.

3. I learn more about how to make the most of my college experience by using the GEFP.

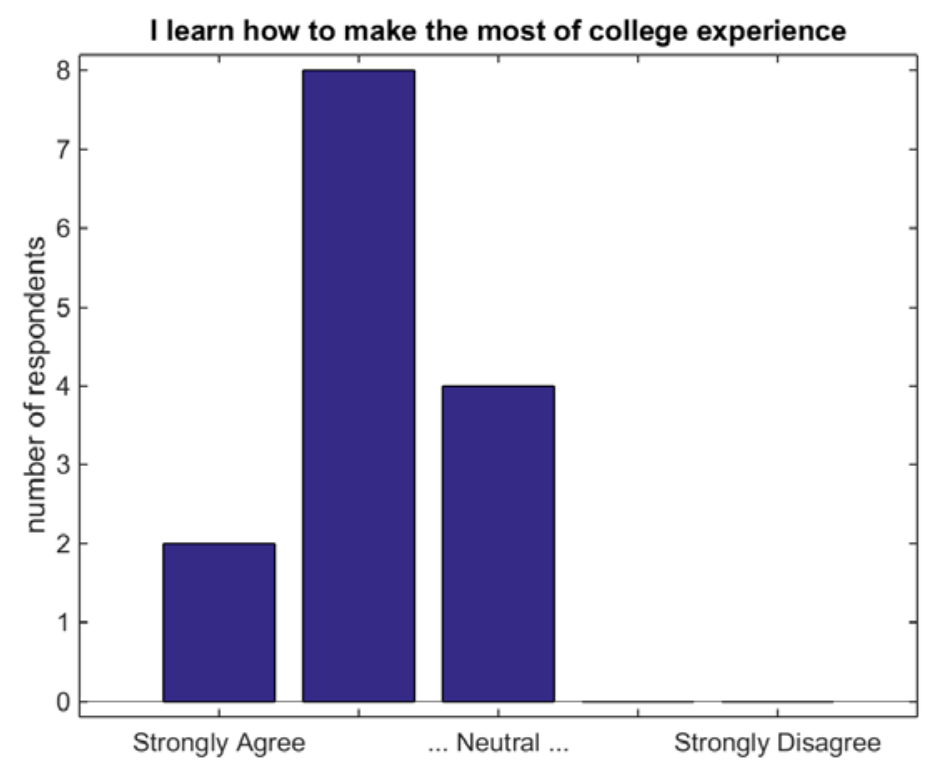

Figure 6

5. I have a better understanding of what I need to become a successful engineer by using the GEFP 


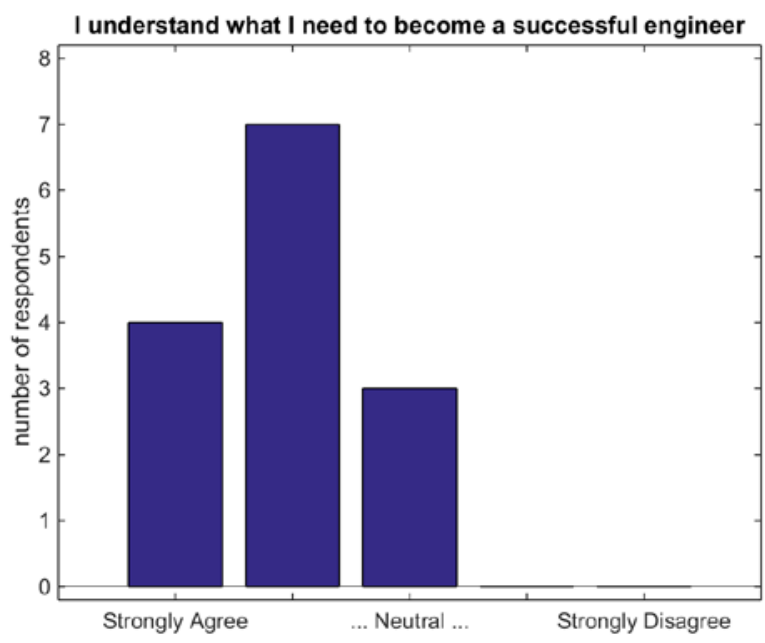

8. I feel the GEFP is more INCONVENIENT than it is useful

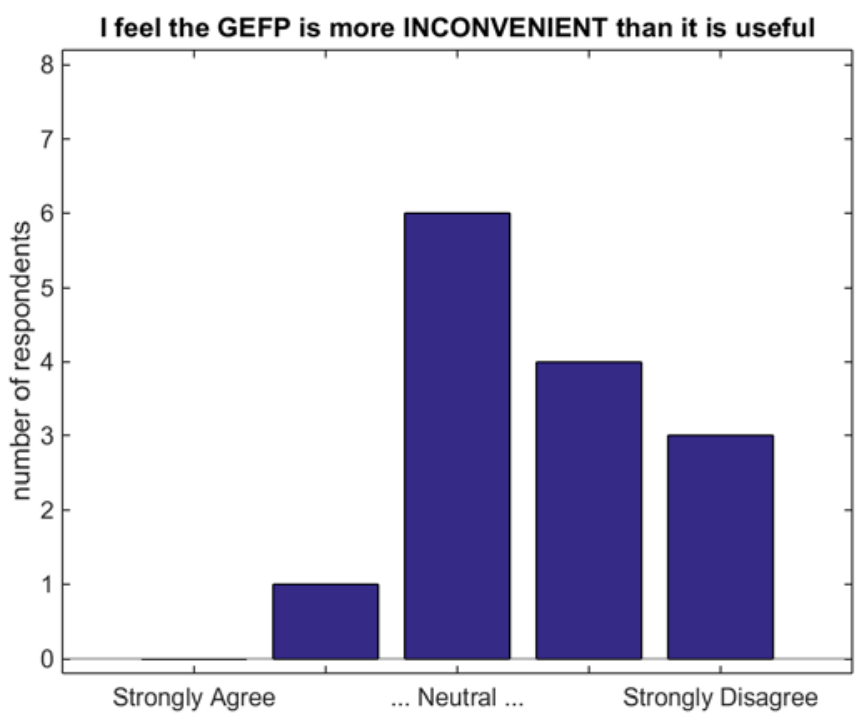

Finally, students were asked "What do you think is the most useful feature of the GEFP?" to which the students gave the following responses:

- Its easily accessible

- The fact that you can keep track of what you have done for your education

- The links that when clicked direct us to the page where that one item from the checklist is all about

- The comment feature

- Check list of tasks needed to be completed.

- Recommended things to join

- Learning about your potential

- The Scholarships box

- That it gave us a checklist of all that had/has to be done to succeed.

- Commenting 
- The meetings with the Advisors

We used a web request logger to track the access of GEFP Online by the students from 10/30/2015 to 1/24/2016. During this period, 18 students visited the website. The median length of each visit, defined as the time between the first page request and the last, is about 7 minutes and a half. The median number of page request is 7 , and most page requests are for checking off milestones and viewing flight plans.

We find these numbers encouraging for several reasons. First, 58\% (i.e. 18 out of 31) of the students in the pilot cohort visited the website during this 3-month period even though they were not required to do so. Secondly, most students spent at least several minutes on their flight plan page, which means they actually read their flight plan - in other words, the flight plan serves its purposes of being an information hub and a roadmap for the students. This is also consistent with the responses of the survey question \#3 where most students found that GEFP helped them gain a better understanding of how to become a successful engineer. Thirdly, all but three students checked at least one milestone and a handful of students used the comment feature, which indicates that they want to use GEFP as a tool to help keeping track of their college career.

One concern we have after examining the data is that almost all the visits to GEFP Online happened during the Fall 2015 quarter. After the holidays, the students seemed to have forgotten about the GEFP, as there was only one visit to the website in the Winter 2016 quarter (from $01 / 04 / 2016-01 / 24 / 2016$. This is not uncommon in student advisement - students are often not aware of or forget to use educational tools and resources that are available to them. As advisors incorporate the GEFP more as a part of their normal advising practice, we expect students will be better encouraged and reminded to use the GEFP on their own.

\section{Conclusions}

GEFP Online was pilot tested on 32 students in the inaugural year of the First-Year Experience at California State University, Los Angeles. Students received the GEFP tool favorably. Their definition of the GEFP aligned closely with the actual purpose for which the GEFP was designed, and students valued all the features built into the GEFP design. These findings have encouraged us to move forward with GEFP mobile app development and to scale up GEFP use to more advisors across the College. Future assessments will address how conversations with advisors changed as a result of the GEFP online.

\section{Acknowledgments}

The authors would like to thank Rudy Ramirez and Candi Marsh and the ECST Advisement Center for providing valuable feedback on GEFP Online. The idea for a multiple pathway advising matrix came from Francisco Castillo of San Francisco State University. This work was funded by the CSU STEM Collaborative grant awarded by the Leona M. and Harry B. Helmsley Charitable Trust. 


\section{References}

[1] B. B. Crookston, "A developmental view of academic advising as teaching.," NACADA Journal, vol. 14, pp. 5-9, 1994.

[2] R. J. Light, Making the most of college: students speak their minds. Cambridge, MA: Harvard University Press, 2001.

[3] J. K. Drake, "The role of academic advising in student retention and persistence," About Campus, pp. 8-12, 2011.

[4] A. Young-Jones, "Academic advising: does it really impact student success?," Quality assurance in college education, vol. 21, pp. 7-19, 2013. 